\title{
Gambaran pengetahuan mahasiswa Fakultas Kedokteran Universitas Sam Ratulangi tentang glaukoma
}

\author{
${ }^{1}$ Andri Theja \\ ${ }^{2}$ Vera Sumual \\ ${ }^{2}$ Yamin Tongku
}

\author{
${ }^{1}$ Kandidat Skripsi Fakultas Kedokteran Universitas Sam Ratulangi Manado \\ ${ }^{2}$ Bagian Ilmu Kesehatan Mata Fakultas Kedokteran Universitas Sam Ratulangi - \\ RSUP Prof. Dr. R. D. Kandou Manado \\ Email: andretheja@gmail.com
}

\begin{abstract}
This study aimed to determine the knowledge about glaucoma of students of Faculty of Medicine, University of Sam Ratulangi Manado. This was a descriptive survey study by using questionnaire. This study was conducted at the Faculty of Medicine, University of Sam Ratulangi from October 2015 until December 2015. There were 81 respondents. Respondents were obtained by stratified random sampling in each batch, and in each batch we used simple random sampling. The results showed that the knowledge categories of students about glaucoma were as follows: moderate category in 57 respondents (70.4\%), good category in 2 respondents (2.4\%), and poor category in 22 respondents (27.2\%). Conclusion: In this study, most of the students of Faculty of Medicine, University of Sam Ratulangi Manado had moderate category of knowledge about glaucoma.
\end{abstract}

Keywords: glaucoma, student knowledge

\begin{abstract}
Abstrak: Penelitian ini bertujuan untuk mengetahui pengetahuan mahasiswa Fakultas Kedokteran Universitas Sam Ratulangi tentang glaukoma. Jenis penelitian yang dilakukan ialah survei deskriptif, dengan membagikan kuesioner pengetahuan kepada responden. Penelitian ini dilakukan di Fakultas Kedokteran Universitas Sam Ratulangi sejak bulan Oktober sampai Desember 2015 dengan responden sebanyak 81 orang. Responden diperoleh berdasarkan teknik stratified random sampling pada masing-masing angkatan, kemudian untuk pengambilan sampel di tiap angkatan digunakan teknik simple random sampling. Hasil penelitian memperlihatkan kategori pengetahuan mahasiswa sebagai berikut: pengetahuan kategori sedang sebanyak 57 responden (70,4\%), kategori baik sebanyak 2 responden $(2,4 \%)$ dan kategori kurang sebanyak 22 responden (27,2\%). Simpulan: Dalam penelitian ini, sebagian besar mahasiswa Fakultas Kedokteran Universitas Sam Ratulangi mempunyai pengetahuan mengenai glaukoma dengan kategori sedang.
\end{abstract}

Kata kunci: glaukoma, pengetahuan mahasiswa

Glaukoma berasal dari kata Yunani "glaukos" yang berarti hijau kebiruan, yang memberikan kesan warna tersebut pada pupil penderita glaukoma. ${ }^{1}$ Glaukoma adalah suatu keadaan dimana tekanan intraokuler (tekanan bola mata) seseorang demikian tinggi atau tidak normal sehingga merusak saraf optik dan mengakibatkan gangguan pada sebagian atau seluruh lapang pandang atau buta. ${ }^{2}$ Glaukoma merupakan penyebab kebutaan kedua terbanyak setelah katarak diseluruh dunia. ${ }^{3}$ Sebanyak 4,5 juta orang atau sekitar $12 \%$ dari total kebutaan didunia, disebabkan oleh glaukoma. ${ }^{4}$ Berdasarkan Survei Kesehatan Indera tahun 1993-1996, sebesar 
$1,5 \%$ penduduk Indonesia mengalami kebutaan dengan prevalensi kebutaan akibat glaukoma sebesar $0,20 \% .^{3}$ Angka kebutaan yang diakibatkan oleh glaukoma memang tidak terlalu tinggi, namun glaukoma merupakan permasalahan yang sangat serius. Hal ini dikarenakan glaukoma yang terlambat ditangani akan mengakibatkan kebutaan yang bersifat permanen, atau tidak dapat diperbaiki (irreversible).

Program Studi Pendidikan Dokter (PSPD) Fakultas Kedokteran (FK) Universitas Sam Ratulangi (Unsrat) merupakan satu-satunya institusi pendidikan dokter yang ada di Sulawesi Utara. Lulusan dokter dari PSPD FK Unsrat nantinya akan berperan sebagai dokter di pusat pelayanan kesehatan primer yang pasti akan berhadapan langsung dengan kasus glaukoma, maka pengetahuan mahasiswa mengenai glaukoma haruslah memadai. Jikalau pengetahuan mereka kurang, maka deteksi dini pada pasien yang datang dengan gejala dan tanda glaukoma sulit ditegakkan. Hal ini akan berdampak pada keterlambatan penanganan, sehingga akan menyebabkan komplikasi yang merugikan diri pasien.

Penelitian ini bertujuan untuk mengetahui gambaran pengetahuan mahasiswa Fakultas Kedokteran Universitas Sam Ratulangi tentang Glaukoma.

\section{METODE PENELITIAN}

Penelitian ini termasuk dalam survei deskriptif untuk mengetahui pengetahuan mahasiswa kedokteran Universitas Sam Ratulangi tentang glaukoma. Pendekatan yang digunakan penelitian ini ialah potong lintang. Penelitian ini berlangsung selama bulan September 2015 sampai November 2015 di Fakultas Kedokteran Universitas Sam Ratulangi. Sampel pada penelitian ini ialah mahasiswa Fakultas Kedokteran Universitas Sam Ratulangi angkatan 2013, angkatan 2014, dan angkatan 2015. Penghitungan jumlah sampel dilakukan dengan menggunakan rumus sehingga diperoleh 81 sampel. Pengambilan sampel dengan menggunakan teknik stratified random sampling. Sampel tersebut kemudian didistribusikan merata pada setiap angkatan sehingga di setiap angkatan diperoleh masing-masing 27 sampel.

\section{HASIL PENELITIAN}

Proses pengambilan data untuk penelitian ini telah dilakukan menggunakan instrumen angket yang telah diisi oleh responden di tempat tanpa dibawa pulang ke rumah. Hasil angket dianalisis dan dipaparkan dalam bentuk tabel distribusi

Responden penelitian ini ialah mahasiswa Fakultas Kedokteran Unsrat angkatan 2013, 2014, dan 2015. Jumlah populasi secara keseluruhan ialah 450. Jumlah responden yang diambil 81 orang dengan pembagian setiap angkatan 27 orang. Dari keseluruhan responden yang ada, diperoleh gambaran mengenai karakteristiknya meliputi jenis kelamin dan usia.

Tabel 1. Distribusi responden berdasarkan usia

\begin{tabular}{ccc}
\hline Usia & Jumlah & $(\%)$ \\
\hline 16 tahun & 1 & 1,2 \\
17 tahun & 17 & 21 \\
18 tahun & 26 & 32,1 \\
19 tahun & 22 & 27,2 \\
20 tahun & 15 & 18,5 \\
Total & 81 & 100 \\
\hline
\end{tabular}

Tabel 2. Distribusi responden berdasarkan jenis kelamin

\begin{tabular}{ccc}
\hline Jenis kelamin & Jumlah & $(\%)$ \\
\hline Perempuan & 43 & 53,1 \\
Laki-laki & 38 & 46,9 \\
Total & 81 & 100 \\
\hline
\end{tabular}

Dalam penelitian ini, terdapat 10 pertanyaan mengenai pengetahuan tentang Glaukoma. Data lengkap distribusi frekuensi jawaban angket responden pada variabel pengetahuan dapat dilihat pada tabel dibawah ini 
Tabel 3. Distribusi responden berdasarkan jawaban angket pengetahuan glaukoma

\begin{tabular}{ccccc}
\hline \multirow{2}{*}{ Pertanyaan } & \multicolumn{4}{c}{ Jawaban Responden } \\
\cline { 2 - 5 } & \multicolumn{3}{c}{ Benar } & \multicolumn{3}{c}{ Salah } \\
\cline { 2 - 5 } & $\mathrm{f}$ & $\%$ & $\mathrm{f}$ & $\%$ \\
\hline Definisi Glaukoma & 53 & 65,4 & 28 & 34,6 \\
Gejala umum Glaukoma kronik & 8 & 9,9 & 73 & 90,1 \\
Faktor risiko penting Glaukoma & 42 & 51,9 & 39 & 48,1 \\
Tekanan intraokular normal & 51 & 63 & 30 & 37 \\
Pemeriksaan diagnostik Glaukoma & 57 & 70,4 & 24 & 29,6 \\
Komplikasi Glaukoma & 49 & 60,5 & 32 & 39,5 \\
Jadwal pemeriksaan mata & 16 & 19,8 & 65 & 80,2 \\
Klasifikasi Glaukoma & 28 & 34,6 & 53 & 65,4 \\
Tujuan utama pengobatan Glaukoma & 37 & 45,7 & 44 & 54,3 \\
Penyebab kebutaan di dunia & 29 & 35,8 & 52 & 64,2 \\
\hline
\end{tabular}

Tabel 4. Distribusi responden berdasarkan pengetahuan mengenai glaukoma

\begin{tabular}{ccc}
\hline Pengetahuan & $\begin{array}{c}\text { Jumlah } \\
\text { responden }\end{array}$ & (\%) \\
\hline Baik & 2 & 2,4 \\
Sedang & 57 & 70,4 \\
Kurang & 22 & 27,2 \\
Total & 81 & 100 \\
\hline
\end{tabular}

Tabel 5. Distribusi tingkat pengetahuan responden berdasarkan jenis kelamin

\begin{tabular}{cccc}
\hline \multirow{2}{*}{ Pengetahuan } & \multicolumn{2}{c}{ Jenis kelamin } & \multirow{2}{*}{ Total } \\
\cline { 2 - 3 } & Laki-laki & Perempuan & \\
\hline Baik & 1 & 1 & 2 \\
Sedang & 25 & 32 & 57 \\
Kurang & 12 & 10 & 22 \\
Total & 38 & 43 & 81 \\
\hline
\end{tabular}

Tabel 6. Distribusi tingkat pengetahuan responden berdasarkan angkatan

\begin{tabular}{cccccccc}
\hline & \multicolumn{8}{c}{ Angkatan } & \multirow{2}{*}{ Total } \\
\cline { 2 - 6 } Pengetahuannnnnnnnnnn & \multicolumn{2}{c}{2013} & \multicolumn{9}{c}{2014} & \multicolumn{2}{c}{2015} & \\
\cline { 2 - 7 } & $\mathrm{f}$ & $\%$ & $\mathrm{f}$ & $\%$ & $\mathrm{f}$ & $\%$ & \\
\hline Baik & 1 & 3,7 & 0 & 0 & 1 & 3,7 & 2 \\
Sedang & 17 & 63 & 21 & 77,8 & 19 & 70,3 & 57 \\
Kurang & 9 & 33,3 & 6 & 22,2 & 7 & 26 & 22 \\
Total & 27 & 100 & 27 & 100 & 27 & 100 & 81 \\
\hline
\end{tabular}

Tabel 7. Distribusi tingkat pengetahuan responden berdasarkan usia

\begin{tabular}{|c|c|c|c|c|c|c|c|c|c|c|c|}
\hline \multirow{3}{*}{ Pengetahuan } & \multicolumn{10}{|c|}{ Usia (tahun) } & \multirow{3}{*}{ Total } \\
\hline & \multicolumn{2}{|c|}{16} & \multicolumn{2}{|c|}{17} & \multicolumn{2}{|c|}{18} & \multicolumn{2}{|c|}{19} & \multicolumn{2}{|c|}{20} & \\
\hline & $\mathrm{F}$ & $\%$ & $f$ & $\%$ & $\mathrm{f}$ & $\%$ & $\mathrm{f}$ & $\%$ & $\mathrm{f}$ & $\%$ & \\
\hline Baik & 0 & 0 & 1 & 5,9 & 0 & 0 & 0 & 0 & 1 & 6,7 & 2 \\
\hline Sedang & 1 & 100 & 11 & 64,7 & 20 & 76,9 & 16 & 72,7 & 9 & 60 & 57 \\
\hline Kurang & 0 & 0 & 5 & 29,4 & 6 & 23,1 & 6 & 27,3 & 5 & 33,3 & 22 \\
\hline Total & 1 & 100 & 17 & 100 & 26 & 100 & 22 & 100 & 15 & 100 & 81 \\
\hline
\end{tabular}




\section{BAHASAN}

Usia responden bervariasi antara 1620 tahun. Usia responden terbanyak pada umur 18 tahun (26 responden) dan yang terkecil ialah 16 tahun (1 responden). Jenis kelamin yang terbanyak ialah perempuan sebanyak 43 orang $(53,1 \%)$ sedangkan responden laki-laki sebanyak 38 orang (46,9\%). Hal ini dikarenakan dalam populasi jumlah perempuan lebih banyak dari laki-laki sehinggga responden yang terambil juga lebih banyak perempuan.

Dari hasil penelitian diperoleh sebanyak 53 responden (65,4\%) telah memiliki pengetahuan yang baik tentang definisi glaukoma dan sebanyak 57 responden $(70,4 \%)$ telah menjawab dengan benar mengenai pemeriksaan yang diperlukan untuk mendiagnosis glaukoma. Di samping itu, sebanyak 42 responden (51,9\%) telah mengetahui faktor risiko penting dari glaukoma dan 49 responden (60,5\%) telah menjawab dengan benar tentang komplikasi yang akan didapat pada pasien glaukoma bila tidak diterapi. Sebanyak 51 responden (63\%) juga telah mengetahui tekanan intraokular normal yaitu sebesar 10-21 mmHg dan 37 responden $(45,7 \%)$ telah menjawab dengan benar tujuan utama pengobatan glaukoma. Di sisi lain, 28 responden (34,6\%) telah mengetahui klasifikasi dari glaukoma dan sebanyak 8 responden (9,9\%) yang mengetahui gejala umum dari glaukoma kronik. Sebanyak 16 responden (19,8\%) mengetahui jadwal rutin pemeriksaan mata dan 29 responden $(35,8 \%)$ telah menjawab dengan benar penyebab kebutaan di dunia yaitu katarak.

Secara keseluruhan diperoleh sebanyak 2 responden (2,4\%) yang berpengetahuan baik, 57 responden $(70,4 \%)$ yang berpengetahuan sedang, dan 22 responden $(27,2 \%)$ yang berpengetahuan kurang. Dari hasil tersebut terlihat bahwa mayoritas pengetahuan tentang glaukoma pada mahasiswa FK UNSRAT angkatan 2013, angkatan 2014, dan angkatan 2015 berada pada tingkat sedang. Menurut asumsi peneliti, hal ini mungkin disebabkan bahwa angkatan 2013, angkatan 2014, dan angkatan 2015 belum menerima materi perkuliahan mengenai glaukoma. Informasi akan memberikan pengaruh pada pengetahuan seseorang, sehingga dalam kaitannya dengan hasil yang didapat, persentase pengetahuan responden yang baik akan lebih besar bila sudah mendapat materi perkuliahan mengenai glaukoma.

Secara umum, responden perempuan memiliki pengetahuan yang lebih baik dibandingkan laki-laki. Perempuan secara psikologi lebih termotivasi dan lebih rajin dalam hal belajar dan bekerja dari pada laki-laki. Hal ini yang membuat prestasi akademik perempuan lebih baik dibandingkan laki-laki. ${ }^{5}$ Penelitian yang dilakukan di Universias Hertfordshire, Inggris oleh Laws didapatkan hasil tingkat konsentrasi perempuan lebih baik dibandingkan laki-laki. Tingkat konsentrasi yang lebih baik akan membuat informasi yang didapatkan seseorang lebih mudah diingat dan dipahami seseorang. ${ }^{6}$ Hal ini yang menyebabkan tingkat pengetahuan pada perempuan lebih baik dari laki-laki.

Distribusi tingkat pengetahuan berdasarkan angkatan, angkatan 2014 memiliki tingkat pengetahuan sedang paling banyak diikuti angkatan 2015 dan angkatan 2013. Angkatan 2013 dan angkatan 2015 memiliki jumlah responden dengan tingkat pengetahuan baik yang sama yaitu sebanyak 1 responden dan angkatan 2013 memiliki jumlah reponden dengan tingkat pengetahuan kurang yang terbanyak yaitu sebanyak 9 responden, diikuti oleh angkatan 2015 sebanyak 7 orang dan angkatan 2014 sebanyak 6 orang. Hal ini menunjukkan bahwa pengetahuan seseorang tidak didasarkan pada lamanya masa perkuliahan yang telah diikuti, tetapi lebih kepada minat seseorang. Minat menjadikan seseorang untuk mencoba dan menekuni suatu hal dan pada akhirnya diperoleh pengetahuan yang lebih dalam.

Tingkat pengetahuan jika dihubungkan dengan usia responden, maka pada kelompok usia 17 tahun dan 20 tahun masing-masing sebanyak 1 responden memiliki pengetahuan yang baik. 
Kelompok usia 18 tahun memiliki tingkat pengetahuan sedang paling banyak yaitu sebanyak 20 responden dan tingkat pengetahuan kurang paling banyak sebanyak 6 responden. Hal ini menunjukkan bahwa usia tertinggi pada penelitian ini bukanlah indikasi pengetahuan seseorang semakin baik. Usia muda belum tentu memiliki pengetahuan yang lebih rendah dibandingkan dengan usia yang lebih tua, begitu juga sebaliknya. Umur memang merupakan salah satu faktor dalam menentukan pengetahuan seseorang, tetapi umur bukanlah satu-satunya faktor penentu dalam menentukan pengetahuan seseorang semakin baik. Selain umur, faktor lain yang memengaruhi pengetahuan seseorang adalah pendidikan, pekerjaan, minat, pengalaman, kebudayaan dan informasi. ${ }^{7}$

\section{SIMPULAN}

Dari hasil penelitin dan bahsan dapat disimpulkan bahwa pengetahuan mahasiswa Fakultas Kedokteran Universitas Sam Ratulangi tentang glaukoma sebagian besar berada pada kategori sedang diikuti kategori kurang dan baik. Secara umum, responden perempuan memiliki pengetahuan yang lebih baik dibandingkan lakilaki.

\section{SARAN}

Perlu dilakukan penelitian lanjutan untuk memantau gambaran pengetahuan mahasiswa FK Unsrat tentang glaukoma.
Untuk para mahasiswa FK Unsrat agar lebih membekali diri dengan pengetahuan tentang glaukoma serta mengisi waktu luang dengan memgembangkan minat membaca yang lebih baik.

\section{DAFTAR PUSTAKA}

1. Ilyas S. Ilmu Penyakit Mata (4th ed). Jakarta: Balai Penerbit FKUI, 2012; p: 216-21.

2. Ilyas S. Glaukoma (Tekanan Bola Mata Tinggi) (3rd ed). Jakarta: Sagung Seto, 2007.

3. Pusat Data dan Informasi Kementerian Kesehatan RI 2015. Available from: http://www.depkes.go.id/resources/do wnload/pusdatin/infodatinglaukoma.pdf [Accessed: September, 14, 2015 ]

4. World Health Organization. Glaucoma. Available from: http://www.who.int/blindness/causes/ priority/en/index6.html [Accessed: September, $14^{\text {th }} 2015$ ]

5. Awaliah. 2011. Perbedaan Gender. Yogyakarta: Universitas Mercubuana. Diunduh dari www.fpsi.mercubuana.ac.id pada tanggal 2 November 2015

6. Rahman D. 2009. Perempuan Lebih Baik Dibandingkan Pria Dalam Multitasking Jobs. Diunduh dari www.psikologi.or.id pada tanggal 2 November 2015

7. Mubarak WI. Promosi Kesehatan Untuk Kebidanan. Jakarta: Salemba Medika, 2012. 